\title{
A narração de alteridade na ficção e na grande reportagem: apontamentos sobre os modos de representação do outro na televisão brasileira
}

\section{The narration of alterity in fiction and in- depth reporting: considerations on structures and strategies of the representation of the other in Brazilian television}

José Augusto Mendes Lobato ${ }^{1}$ 


\section{Resumo}

O trabalho busca mapear, discutir e elencar marcos estruturais capazes de delimitar a narrativa de alteridade como um formato transversal do ambiente televisivo, com foco em dois gêneros: a grande reportagem jornalística e a ficção seriada. Com base nas ciências da linguagem e nos estudos culturais e da imagem, são adotadas três categorias de análise - as estratégias testemunhais/evenemenciais, os jogos de oposição e as interações entre ficcionalização e factualização - para examinar quatro telenovelas e 16 edições do programa jornalístico Globo Repórter. Ao fim, são mapeados oito elementos estruturantes da enunciação de alteridade, incluindo a retórica testemunhal, a intriga fundada no outro, a marcação de fronteiras e a contra-narração, reiterando as funções de reconfiguração e disciplinarização da experiência na televisão contemporânea.

Palavras-chave

Televisão, jornalismo, ficção seriada, alteridade, análise narrativa.

\section{Abstract}

The objective of this article is to identify, discuss and list structural elements capable of delimiting the narrative of alterity as a transversal format of television, focusing on two genres: in-depth reporting and serial fiction. Based on language sciences and on cultural and image studies, this study uses three categories of analysis - testimonial/ evenemential strategies, the construction of oppositions, and the interactions between fictionalization and factualization - to examine four telenovelas and 16 editions of the journalistic program Globo Repórter. Finally, we identify eight structural elements of the enunciation of alterity, including the testimonial rhetoric, the alterity-based narrative intrigue, the construction of boundaries and counter-narration, reiterating the functions of reconfiguration and disciplinarization of experience in contemporary television.

\section{Keywords}

Television, journalism, serial fiction, alterity, narrative analysis. 
Dentro da longa tradição de estudos que colocam em diálogo os campos da linguagem, da cultura e, mais recentemente, das mídias, uma preocupação central tem sido compreender como reconfiguramos modos de ver, viver e agir no mundo como consequência dos processos de representação. De nossas formações mentais aos relatos e imagens que difundimos, o que mudou em nossa compreensão do ambiente circundante com a profusão de dispositivos comunicacionais? Como delimitamos ambientes familiares e nos habituamos a lê-los, dentro e fora de telas e aparelhos? De que maneira o hábito de narrar e ouvir histórias se comporta no fluxo audiovisual, reinventando imaginários e formas de ver e demarcar o próximo e o distante?

Essas questões têm, mais que respostas, problemas compartilhados. E todos, por sua vez, convergem para um propósito central neste texto: colocar em crise a ideia de que somente hoje se convive com uma inexorável dependência dos processos de representação. Com base em reflexões interdisciplinares das ciências da linguagem, entende-se que, como alerta Serge Moscovici (2003, p. 40), "todas as interações humanas, surjam elas entre duas pessoas ou entre dois grupos, pressupõem representações" - e que é a partir dos recortes simbólicos que formamos sentidos de proximidade/pertencimento e, consequentemente, definimos as fronteiras e os limiares do não-familiar. E é dentro desse jogo, no qual nos movemos cotidianamente, que se situa o objeto de análise deste trabalho - a saber, a construção de narrativas da alteridade como um impulso das produções televisivas contemporâneas, levando-nos a uma experiência mediada de descoberta.

Conectado aos resultados de uma pesquisa de doutorado, este texto busca propor uma reflexão sobre estratégias que regem a representação do outro em produtos televisuais brasileiros, tomando, como objeto de estudo específico, os gêneros jornalístico e de ficção seriada, nos formatos da grande reportagem e da telenovela. Os resultados que serão debatidos e apresentados a seguir apontam para oito elementos ligados à enunciação de alteridade - um conjunto de marcos estruturais que, por ser identificável em dois gêneros representativos da produção 
televisiva, sinaliza a narração do outro como um modo de contar presente de forma transversal nas mídias.

\section{Fundamentos de linguagem: a representação, a narrativa e a questão do outro}

A combinação de diferentes campos, como a filosofia, a narratologia e a psicologia, faz das ciências da linguagem um território fértil para compreendermos de que forma operam os processos de enunciação - tendo os conceitos de representação, narrativa, identidade e alteridade como eixos essenciais.

O processo de observar o mundo, transpô-lo em narrativas visuais ou verbais e construir imagens a respeito do que é vivido dialoga diretamente com a noção de representação - tratada também no pensamento aristotélico e que, já no século XX, ganhou novos contornos com as reflexões da psicologia. Em linha com Moscovici (2003), entende-se que não há como escapar das representações sociais para se ler o mundo, tanto nas conversações cotidianas como na comunicação por dispositivos tecnológicos. Para o autor, a dinâmica das relações opera como "uma dinâmica de familiarização, onde os objetos, pessoas e acontecimentos são percebidos e compreendidos em relação a prévios encontros e paradigmas" (MOSCOVICI, 2003, p. 55); não à toa, dirá que a finalidade de toda representação é tornar familiar o não familiar ou a não familiaridade, produzindo consensos que fundamentam nosso senso comum - e também prescrições, em uma lógica que podemos denominar (em diálogo com os estudos do discurso) disciplinar e domesticadora do visível.

Os estudos culturais também aportam contribuições à questão, já que é pela circulação de narrativas e relatos que as identidades são forjadas e reformuladas. Essa função identitária do narrar - que se soma a outras funções, como a disciplinar, a lúdica e a informativo-cognitiva - é especialmente importante por lançar luz sobre os processos por meio dos quais mobilizamos, dentro e fora das mídias, imaginários a respeito do eu/nós e do outro; afinal, como diz Woodward (2000, 
p. 17), "é por meio dos significados produzidos pelas representações que damos sentido à nossa experiência e àquilo que somos".

As maneiras com que se faz isso em uma narrativa, seja de ficção ou não ficção, dialogam com a ideia de que sempre é preciso estabelecer distinções e polos opositivos. Preocupado com tal questão, Bhabha (1998) estabelece conceitos como os de tradução e contra-narrativa. Estas "continuamente evocam e rasuram suas fronteiras totalizadoras", e "perturbam aquelas manobras ideológicas através das quais 'comunidades imaginadas' recebem identidades essencialistas" (BHABHA, 1998, p. 211).

Adicionalmente, também devemos atentar para os achados da filosofia da linguagem e dos estudos do discurso que posicionam a produção da identidade e a própria atividade discursiva como formas de exercício e disputa pelo poder. Assim, entendemos a demarcação da identidade e da alteridade como processos arbitrários que sempre resultam na normatização de condutas, na construção de "embates e coerções, interdições e exclusões" (GOMES, 2003, p. 45) e na definição do visível e do vivível, tanto em relação ao eu/nós quanto em relação ao(s) outro(s).

Fazemos breve referência e esses estudos para delinear alguns conceitoschave para a reflexão proposta. O primeiro é a própria ideia da narrativa de alteridade como categoria passível de análise estrutural que visa à sua compreensão. De forma complementar à narrativa nacional dos estudos culturais, entendemos esta como um tipo de enunciado que tem, no centro de sua intriga ou de seu conflito - noção que emprestamos dos estudiosos da narrativa, como Todorov (2003) -, o processo de contato, tradução e reconhecimento de universos cultural ou geograficamente distantes.

Assim como a narrativa da nação, a de alteridade pode - e tende a - ser preexistente à consciência individual. Atua de modo convencional e prescritivo, como diz Moscovici (2003), ou disciplinar, nos termos de Foucault (1996) e Gomes (2003), pois nos ensina a enxergar o outro sob determinado ângulo, orientando 
consensos sobre ele produzidos e definindo seus traços que são trazidos à luz na representação. E pode ocorrer tanto nos relatos que nos apresentarão um Brasil distante, idealizado e, por vezes, exótico/"estrangeirizado" - dentro da categoria que definimos como alteridade sociocultural - quanto em narrativas que nos levarão a uma jornada rumo a regiões espacialmente distantes (alteridade geográfica), fundadas na ancoragem de um outro que, se não exclusivamente, é primariamente exibido por meio de textos e imagens voltados à tradução do não-familiar.

\section{Imagem e experiência de alteridade em narrativas televisuais}

O propósito de estudar a representação do outro na televisão também nos conduziu a um percurso pelos estudos de imagem. Diversos autores (KAMPER, 2001; DUBOIS, 1994; DEBRAY, 1993; FLUSSER, 2007; 2008; MACHADO, 2002; CATALÀ, 2005) indicam a necessidade de se compreender a progressão histórica dos suportes e seus efeitos cognitivos e sociais.

A discussão dos impactos do imagético sobre a cognição pode ser feita a partir de Vilém Flusser (2007). Em estudos de referência no campo da fotografia e do audiovisual em geral, o autor faz a distinção entre um pensamento conceitual (ou em linha) e um pensamento "por imagens" (em superfície), demonstrando que a conversão (abstração) das coisas em representações é feita de maneira distinta pelas imagens. Por elas, diz-nos o autor, acessamos primeiramente o "concreto" (via materialidade da imagem), diferentemente do texto, para só depois entendermos os conceitos que geraram tal imagem. Por isso, "as mensagens da mídia imagética são mais ricas e as mensagens da mídia conceitual são mais nítidas" (FLUSSER, 2007, p. 115).

Independentemente da crítica que se possa fazer a respeito desse processo, lançada, inclusive, por Flusser em suas obras, as imagens técnicas instauram possibilidades de conhecimento e reconhecimento do mundo que, de certo, potencializam os caminhos para a compreensão da alteridade - seja em gêneros e formatos de ficção, seja nos marcadamente informativos, como é o caso do jornalismo e do audiovisual documental. 
A partir da perspectiva de três correntes de reflexão sobre as imagens, buscamos definir uma categoria específica, que se soma às noções de narrativa de alteridade e de alteridades geográficas e socioculturais para fundamentarmos nossa análise sobre o Globo repórter e as telenovelas brasileiras: a de imagem evenemencial. De forma breve, a entendemos como registro que se constitui, simultaneamente, como produto e fio condutor da experiência de contato com o mundo - ou seja, como captura do mundo, a partir da ideia de que um testemunho ou vivência de alteridade a produziu, e como moldura, considerando sua dimensão prescritiva e organizativa da experiência do ambiente exterior.

Erguemos a ideia de evenemencialidade a partir de três correntes de contribuição teórico-crítica aos estudos de imagem. Uma associa-se aos debates de Philippe Dubois (1994) sobre o caráter indicial e referencial de toda imagem, tida como um "traço do real" capaz de dar materialidade ao registro do mundo; outra é a reflexão de Debord (1997) e outros a respeito da profusão do imagético e seus impactos em termos de sociabilidade e experiência; e a terceira, mais próxima de nosso propósito, é a teoria da imagem complexa, definida por Català (2005) como um regime perceptivo peculiar, no qual a multiplicidade, a interrelação referencial e a capacidade de renovação das imagens gera uma nova cultura visual.

\section{O jornalismo e a ficção seriada em televisão: referenciais de base}

Por meio de alguns trabalhos, dentre os quais destacamos os de Sodré (2009), Gomes (2003), Sponholz (2009) e Medina (1988), analisa-se o jornalismo como um gênero de discurso mais amplo, apoiado em noções e parâmetros que abrangem a tensão entre objetividade/referencialidade e narratividade e alguns de seus pressupostos históricos.

Conforme nota Sponholz (2009), o discurso jornalístico emula técnicas de apreensão de realidade do senso comum - sua maneira de narrar - e as alia a métodos oriundos do meio científico, visando à produção de relatos minimamente capazes de dar conta da realidade objetiva. Dentro dos muitos 
gêneros e formatos jornalísticos informativos, opinativos ou interpretativos - termos adotados nas classificações brasileiras do campo -, elegemos a grande reportagem como central à análise. Adotado pelo Globo repórter, esse formato indica alguns princípios narrativos, por nós discutidos em outro trabalho (LOBATO, 2016, p. 74): a) ampliação espaço-temporal do fato social; b) construção dramática/diegética das cenas (reforço da narratividade); c) reforço da enunciação e da autoria pelo trabalho testemunhal; d) singularização do fato por meio de personagens e histórias de vida; e e) uso de técnicas e índices de ficcionalização. Tais elementos demonstram que, em linha com o que propõe Marcela Farré (2004, p. 167), há espaço e incidência na mídia de um noticiário "ficcionalizado", no qual há um "um narrador que, procurando acima de tudo construir um pacto com o espectador, põe seus saberes para consideração do outro".

No outro eixo de nosso corpus, tomamos a fiç̧ão como um campo de análise sustentado tanto pelos estudos sobre as funções e os "acordos" ou pactos construídos com quem consome textos fictícios - e, aqui, as reflexões de Umberto Eco (1994) são fundamentais - quanto pela análise narrativa e pela pesquisa em torno do formato telenovela. Com base nas definições de Lopes (2009), enxergamos a telenovela como uma legítima narrativa da nação, em um viés que ultrapassa, notavelmente, os fins lúdicos e de entretenimento normalmente associados às narrativas de ficção.

Com base nas ideias de Melo (1988), Baccega (2003), Lopes (2003; 2009), Martín-Barbero (1988) e Campedelli (1987), consideramos cinco grandes traços estruturantes do formato: a) serialidade das tramas; b) referencialidade temática; c) multiplicidade e mutabilidade de tramas; d) espaço-temporalidade múltipla; e e) redundância e recorrência de personagens (tipicidade). Essas marcas do modo de contar peculiar da teleficção brasileira demonstram que, assim como no jornalismo de viés aprofundado da grande reportagem, a telenovela pode ser um lugar de modulação da experiência de conhecimento, ancoragem e objetivação da alteridade. 


\section{Fundamento, método e categorias de análise}

As reflexões anteriormente apresentadas conduziram este trabalho a dois métodos de análise. Por um lado, interessou-nos, em linha com o problema central de pesquisa, identificar elementos estruturantes da construção de alteridade na televisão brasileira - o que estabeleceu a análise narrativa, baseada na busca por achados comuns a diferentes registros de linguagem e ao mapeamento de funções, elementos e operações estilísticas dentro do corpus. Por outro lado, o contato com as reportagens do Globo Repórter e com os capítulos das quatro telenovelas selecionadas para análise fez notar a necessidade de incorporar elementos da análise do discurso, principalmente a partir da identificação de determinadas estratégias valorativas e de produção de mapas de sentido na hora de traduzir e representar o outro.

Com relação ao corpus, foram selecionadas cenas de diversos capítulos das quatro telenovelas e 16 unidades (programas) do Globo Repórter, sendo todos os materiais exibidos entre 2011 e 2014, após mapeamento das produções televisivas de ficção e jornalismo da Rede Globo durante o período. No caso das telenovelas, foi realizada uma observação da grade de ficção veiculada pela emissora de 2011 a 2014, mapeando as produções que abordaram explicitamente universos de alteridade. Foram escolhidas quatro obras: Salve Jorge (20122013), parcialmente ambientada na Turquia; Joia rara (2013-2014), que possui personagens e núcleos no Nepal; Amor, eterno amor (2012), na qual parte da história se passa na fictícia Vila dos Milagres, na Ilha do Marajó, estado do Pará; e Além do horizonte (2013-2014), ambientada em parte na comunidade fictícia de Tapiré, interior do estado do Amazonas.

Quanto ao Globo Repórter, foi definido um universo de 16 programas exibidos entre 2011 e 2014, selecionados por tratarem explicitamente de outros países (alteridade geográfica) ou de regiões do Brasil (alteridade sociocultural). Optou-se por focalizar, nas edições sobre outros países, narrativas distribuídas por diferentes continentes - no caso, Ásia, África e Europa. No caso dos programas sobre o Brasil, foram selecionados aqueles que tratam de biomas (Amazônia, 
Pampa, Mata Atlântica e Pantanal) e, também, os que abordam diferenças culturais, como os programas "Brasil abaixo de zero" e "Cidades jovens do Brasil".

\section{Estruturas da narrativa televisual de alteridade: apontamentos e achados}

Para execução da análise, optamos por trabalhar com três grandes categorias ou eixos, em conexão direta com os marcos teóricos da pesquisa, com o trabalho de observação geral dos programas e com a definição do corpus: a) os trabalhos de autenticação do real a partir do testemunho e dos processos imersivos e evenemenciais em torno da alteridade; b) as estratégias opositivas e a produção de fronteiras e mapas de sentido a respeito do outro; e c) as tensões e oscilações entre estratégias ficcionalizadas e factualizadas na experiência narrada de alteridade.

Desde o início deste trabalho, buscou-se afastar a ideia de um modelo canônico dos princípios e regras de cada formatação ou gênero do discurso; nossa problematização buscou examinar a figuração do outro em diferentes programas televisuais justamente como parte da defesa da existência de um fio, de um nó condutor comum, que modelizava as narrativas de alteridade sem, no entanto, engessá-las. Surpreendeu-nos notar, também, algumas adaptações em determinadas estratégias, conforme o gênero e a dimensão de alteridade - como os jogos opositivos, que têm viés diferente quando se fala de outros países ou de biomas brasileiros nas grandes reportagens.

A seguir, apresentamos uma compilação das oito estratégias identificadas, com os respectivos formatos (grande reportagem ou ficção) e dimensões de alteridade narrada (geográfica ou sociocultural) em que se fizeram mais presentes:

- Intriga fundada na alteridade;

- retórica testemunhal-afetiva;

- narrativas de trajeto;

- adoção de personagens e sujeitos fronteiriços;

- traduções e produção de polos opositivos;

- processos contra-narrativos; 
- valoração do outro e atribuição de sentidos;

- interações ficcionalização versus factualização (hibridismo de linguagens).

O primeiro item diz respeito à conversão do outro na intriga - central ou secundária - que move a narrativa. Em termos narratológicos, a intriga está associada a uma quebra de expectativa, a uma transição ou a um deslocamento que se torna necessário - física ou simbolicamente - na vida das personagens de ficção e, em um escopo mais amplo, no estado das coisas do mundo em si; daí a sinonímia latente entre a intriga, o conflito e a peripécia aristotélica.

Identificamos que transformar o outro não em meio, ou seja, em território a servir à construção da cena, mas sim na própria força motriz de uma história que o toma como pauta ou assunto é um dos caminhos para reforçar a enunciação de alteridade. Todas as viradas importantes de uma trama, nesse caso, estão condicionadas aos universos não familiares e sua capacidade de mobilizar personagens, dramas e sentimentos construídos no âmbito intranarrativo e, também, com o telespectador. Essa estratégia marca presença em todas as 16 grandes reportagens do Globo Repórter analisadas e, em menor medida, nos plots das telenovelas associadas à alteridade geográfica; no caso das obras que abordam o bioma Amazônia, nota-se relevância secundária das personagens e núcleos das vilas de Tapiré (Além do horizonte) e dos Milagres (Amor, eterno amor) para o andamento da história.

Em casos como o programa Globo Repórter, de 29 de abril de 2013, "Amazônia secreta", apresenta-se, na abertura da atração, a proposta de descobrir "um Brasil nunca visto: selvagem, secreto, rico e completamente desconhecido"; na edição sobre a Armênia, de 22 de agosto de 2014, fala-se da descoberta de uma terra "nunca antes mostrada na TV brasileira"; e, no programa sobre o Pampa Gaúcho, de 18 de junho de 2012, propõe-se entender um dos "menos conhecidos biomas brasileiros", algo destacado pelo apresentador Sérgio Chapelin na abertura. 
Nossa perspectiva, a despeito de tais variações, é a de que a figuração do outro na televisão sempre perpassa algum tipo de produção de conflito associada à alteridade. Ela pode ser um ambiente a ser descoberto, um lugar misterioso ou mesmo perigoso, um espaço de vivência para personagens reais e fictícios e seus sentimentos e intimidades, um meio de contar histórias dramáticas e aventuras sobre lugares exóticos e difíceis de se acessar.

O segundo marco estrutural, a retórica testemunhal-afetiva, diz respeito a uma importante estratégia de autenticação do real. Nas narrativas do Globo Repórter, encontramos traços marcantes desse modelo em todos os 16 programas analisados. Nas quatro telenovelas do corpus, também encontramos o testemunhal, em especial nas cenas e sequências que mobilizam o trânsito e a interação entre personagens de diferentes países e regiões.

O testemunho atua como uma operação de sentido ligada à sociabilidade, à construção do efeito de realidade e à produção de verdade no âmbito das narrativas televisuais de alteridade, demarcando não só o eu-estive-lá, tão facilmente encontrado no telejornalismo, mas também um estatuto de credibilidade e de verificação/checagem material do mundo, a partir de alguém que o lê e experimenta. Os testemunhos de contato, assim, se destacam por exibir a interação direta entre culturas. No Globo Repórter, é notável o uso de fontes e entrevistas (como moradores locais, brasileiros expatriados, especialistas, guias de turismo etc.) para isso. É o caso do programa "Moçambique: a África que fala português", exibido em 2 de agosto de 2013, no qual incontáveis moradores locais são entrevistados pela repórter Dulcinéia Novaes para retratar e explicar alguns costumes, tendo como grande elemento facilitador para a apreensão de sentido o uso da língua portuguesa. Na sequência transcrita a seguir, nota-se, inclusive, o recurso de exibição do contato e da experiência direta da repórter - comparando um fruto local a um brasileiro:

Off: Zito Inhamirre, barqueiro, mostra um preparo de atleta. Desce a montanha de areia num instante, e logo volta, trazendo nas mãos um fruto muito comum nesta região, a macoma, e uma bebida preparada com ela. 
Dulcinéia: É tipo um suco?

Zito: Um pouco suco, sim, mas agora está muito doce.

Dulcinéia: Tem álcool?

Zito: Não muito. Queres provar?

Dulcinéia: Será...? [a repórter prova a bebida] Sabe o que lembra um pouquinho? Lá no Brasil, se chama cupuaçu.

Nas telenovelas, nota-se a presença constante da linguagem do testemunho de interação. Salve Jorge, obra de Glória Perez, é o caso mais marcante nesse âmbito. Personagens que transitam entre mundos familiares e distantes - no caso, que se deslocam do Brasil para a Turquia - assumem a posição de transmissores de uma experiência de contato com o outro. Em capítulo exibido no dia 24 de novembro de 2012, por exemplo, a abordagem de um casamento à moda turca se torna cenário para uma sequência testemunhal envolvendo Bianca (Cléo Pires) e outros personagens turcos e brasileiros.

Quanto às narrativas de trajeto, reitera-se a ideia de que o outro é algo a ser desvendado por meio de uma construção narrativa cujo resultado - ou cuja solução do conflito - consiste justamente na chegada e na leitura do ambiente a ser representado, após longo processo de documentação de dificuldades, barreiras, entraves e desafios enfrentados. Tanto no jornalismo como na ficção, notamos a abundância das narrativas de trajeto para explicar, demarcar esforços e lugares de fala, indicar a localização da alteridade e mostrá-la como algo que só é conquistado após amplo esforço físico e/ou intelectual.

Um exemplo marcante ocorre em "Expedição pelo rio Amazonas", série com dois programas. No primeiro, exibido em 12 de agosto de 2011, o repórter José Raimundo chega a provar as águas do Atlântico (fato registrado por imagem) em uma viagem de barco para verificar se ainda estão sob influência do rio. 
rio Amazonas. Vejam só, toda essa água barrenta vem de lá. É ele que manda. É a prova de que ele vai empurrando o mar bem mais pra frente. Eu vou experimentar um pouco pra ver que gosto tem... Não é nem salobra, nem sinal de sal. É água doce no meio do Atlântico.

Aqui, trata-se de um clássico caso de domesticação do visível e de autenticação e produção do efeito de realidade, por meio da vivência mediada dos percalços de quem (repórteres, cinegrafistas, personagens de ficção, apresentadores etc.) lê a alteridade no discurso das mídias.

Assim como na estratégia das narrativas de trajeto, a adoção de personagens e sujeitos fronteiriços como recurso corresponde à necessidade de singularização de toda narrativa - a mesma que move a retórica testemunhal - e figura de forma transversal e homogênea no corpus analisado. Por de meio de personagens e entrevistados estrangeiros ou locais, além de repórteres e apresentadores, o trânsito entre culturas é objetivado em uma figura humana, responsável pelo processo de tradução a partir de estratégias opositivas fundadas na descoberta do outro.

Tal recurso é frequentemente adotado na ficção. Em Joia rara, os monges Sonan (Caio Blat), Tenpa (Ângelo Antônio) e Jampa (Fábio Yoshihara), que viajam ao Brasil, são o foco das interações entre o país e o Nepal, com cenas marcadas por explicações sobre seus valores, costumes, crenças e espiritualidade.

O quinto aspecto corresponde às operações de tradução e produção de polos opositivos. Aqui, fala-se, essencialmente, do trabalho complexo de assimilar os discursos da diferença por meio da assunção de posturas diante do outro, de modos de lê-lo, interpretá-lo e narrativizá-lo. Notamos, aqui, a recorrência de termos, comparações, alusões e formações opositivas clássicas, muitas delas transculturais - como urbanidade versus ruralidade e tradição versus modernidade -, na expressão de repórteres e personagens de ficção, que descrevem e falam dos costumes de determinado ambiente.

Identificamos em nosso corpus variações no desenho das estratégias opositivas segundo essa tensão entre distância e proximidade. Enquanto, nas grandes reportagens jornalísticas sobre regiões do Brasil-outro, vimos a construção 
baseada na ênfase da diferença, ou seja, reforçando traços de distinção, nas narrativas de alteridade geográfica do Globo repórter a ênfase está em uma tentativa de aproximação ou assimilação, por meio de comparativos entre a cultura exógena e a nacional que reforçam valores e assuntos transculturais (religiosidade, fé, desigualdade social). Nas obras de ficção, nota-se a combinação entre as estratégias de aproximação e distanciamento, sendo que os processos de tradução figuram como condições básicas não só para o entendimento do telespectador, mas para a própria modulação da narrativa.

O sexto aspecto identificado por nós dialoga diretamente com os jogos opositivos e diz respeito aos processos contra-narrativos. Em linha com as reflexões de Bhabha (1998), notamos que as dinâmicas de atualização dos discursos de identidade geram uma seleção arbitrária, unificadora e naturalmente simplificadora, que forja narrativas essencialistas e abre margem para o desenho de oposições internas, que revelam as brechas e fissuras a partir das quais a alteridade ressurge no próprio familiar.

Nas narrativas examinadas nesta pesquisa, identificamos que os processos contra-narrativos ocorrem tanto no campo geográfico quanto no sociocultural, com atribuições distintas. No primeiro caso, trata-se de um esforço para buscar imprimir um ar de diversidade às representações construídas sobre um outro país. No eixo sociocultural, as contra-narrativas figuram como a própria justificativa da construção dos biomas brasileiros e das comunidades e cidades do interior do País como exóticas; os esforços opositivos que opõem um Brasil-mesmo e um Brasil-outro aludem à questão da "alteridade do povo-como-um", citada por Bhabha (1998, p. 213).

O sétimo elemento estruturante das narrativas de alteridade, a atribuição de valores, é, decerto, comum a todos os tipos de representação; no entanto, posicionamos esta característica como um marco por identificar sua notável frequência nas narrativas jornalísticas e de ficção como configuradora da própria diferença, associando o ambiente exógeno a aspectos positivos ou negativos que guiam o processo perceptivo e, assim, constroem rotinas, leituras e disciplinas. 
Dessa forma, a valoração da alteridade atuaria como um dispositivo disciplinar, na acepção foucaultiana, visto que atua na conformação do olhar a visadas previamente definidas que facilitam e simplificam o processo de apreensão do outro, reduzindo a polissemia natural em torno de universos culturais alheios, aparando arestas, removendo possibilidades e rotas de desvio.

Na observação das 16 edições do Globo repórter e das telenovelas Joia rara e Salve Jorge, em especial, identifica-se um conjunto de juízos de valor de tônica positiva, associando a alteridade à exuberância, à diversidade cultural, à riqueza de costumes e a valores universais - como elevada espiritualidade, simpatia, cordialidade, beleza geográfica e respeito às tradições; há, inclusive, ideias e terminologias que atravessam ou mesmo se repetem nas narrativas.

Subjacente às demais notações, o oitavo aspecto, que denominamos interações ficcionalização versus factualização, é um elemento de linguagem que, no caso das narrativas de alteridade, serve como indutor de estratégias diegéticas e de autenticação que supõem um complexo processo de reversão do código fundante de cada formato aqui examinado.

Por meio do levantamento de índices de ficcionalização - como os citados por Farré (2004), incluindo a focalização subjetiva do relato, o uso de grafismos, a composição dramática do relato de um fato ou mesmo sua própria "invenção", ou seja, a marcação de um tema narrativo pelo próprio dispositivo televisual e, também, de elementos de factualização, posicionamos a grande reportagem jornalística e a telenovela brasileira como produtos típicos do novo regime realístico da televisão, marcado pela hibridação de linguagens.

\section{Considerações finais}

Acreditamos ter chegado, por meio de nossa investigação, a um conjunto de oito marcos estruturantes das narrativas televisuais de alteridade, capaz de apontar como se apreende, traduz e narra a diferença em diferentes gêneros e formatos. São modelos, técnicas e recursos que denominamos estratégias, em função de seu caráter crucial para a demarcação entre o próximo e o distante e 
a consequente formação de regimes e percursos de leitura que tornam o outro inteligível, compreensível e visível.

Aqui, propomos um exercício que parece se apresentar como estanque e conclusivo; no entanto, cabe-nos reconhecer que - como indicado por Homi Bhabha (1998) - o que marcamos discursivamente nem sempre acompanha com a mesma velocidade as dinâmicas da cultura.

Voltando às clássicas reflexões de Tzvetan Todorov sobre as estruturas narrativas, somos provocados a assumir que, embora haja códigos comuns às diferentes produções da linguagem, as obras que examinamos sempre tratarão de engendrar códigos variantes, diferenças em relação ao que se supõe estável. "O modelo, portanto, nunca é definitivo", nos diz Todorov (2003, p. 10); "o modelo ideal é aquele que tenha algumas traves mestras, mas ofereça ao mesmo tempo certa flexibilidade, para poder variar no momento da aplicação e ser capaz de revelar tanto o repetido quanto o novo".

Acreditando na existência de uma rede de relações que conecta diversos regimes discursivos à hora de traduzir, ancorar e dar sentido a ambientes cultural ou geograficamente distantes, observamos um conjunto de estratégias dinâmicas e recorrentes nas malhas discursivas da televisão. Tal investigação nos parece suficiente para abrir espaço a outros tipos de leitura e crítica sobre a forma com que as produções audiovisuais reconfiguram a experiência de contato com a alteridade - um processo que, como vimos, nos assombra, fascina e convida a mergulhar no mundo, dia após dia, registro após registro, dentro e fora dos enunciados das mídias.

\section{Referências}

BARTHES, R. O rumor da língua. São Paulo: Brasiliense, 1988.

BENEDETI, C. A. A qualidade da informação jornalística: do conceito à prática. Florianópolis: Insular, 2009. 
BHABHA, H. O local da cultura. Belo Horizonte: Editora UFMG, 1998.

CAMPEDELLI, S. Y. A telenovela. São Paulo: Ática, 1987.

CATALÀ, J. M. La imagen compleja: la fenomenologia de las imágenes en la era de la cultura visual. Bellaterra: Universitat Autònoma de Barcelona, 2005.

DEBORD, G. A sociedade do espetáculo. Rio de Janeiro: Contraponto, 1997.

DEBRAY, R. Vida e morte da imagem. Petrópolis: Vozes, 1993.

DUBOIS, P. O ato fotográfico e outros ensaios. Campinas: Papirus, 1994.

ECO, U. Seis passeios pelos bosques da ficção. São Paulo: Companhia das Letras, 1994.

FARO, J. Reportagem: na fronteira do tempo e da cultura. Verso e Reverso, São Leopoldo, v. 27, n. 65, p. 77-83, maio/ago. 2013.

FARRÉ, M. El noticiero como mundo posible. Buenos Aires: La Crujia, 2004.

FLUSSER, V. O mundo codificado. São Paulo: Cosac \& Naify, 2007.

. O universo das imagens técnicas. São Paulo: Annablume, 2008.

. Filosofia da caixa preta. São Paulo: Hucitec, 2011.

FOUCAULT, M. A ordem do discurso. São Paulo: Loyola, 1996.

FREITAS, J. M. Comunicação e psicanálise. São Paulo: Escuta, 1992. 
GOMES, I. (Org.). Televisão e realidade. Salvador: EDUFBA, 2009.

GOMES, M. R. Poder no jornalismo. São Paulo: Hacker; Edusp, 2003. . Comunicação e identificação. Cotia: Ateliê Editorial, 2008.

HALL, S. A identidade cultural na pós-modernidade. Rio de Janeiro: Guaracira, 2001.

KAMPER, D. Imagem. In: WULF, C.; BORSARI, A. (Orgs.). Cosmo, corpo, cultura: enciclopedia antropologica. Milano: Mondadori, 2001.

LOBATO, J. A. M. Jornalismo e narratividade em sintonia: um percurso teóricoconceitual pelos elementos da grande reportagem. Estudos em Jornalismo e Mídia, Florianópolis, v. 13, n. 2, p. 66-77, fev. 2017. doi: http://dx.doi.org/10.5007/19846924.2016v13n2p66.

LOPES, M. I. V. A telenovela brasileira: uma narrativa sobre a nação. Comunicação \& Educação, São Paulo, n. 26, p. 17-34, jan./abr. 2003.

Telenovela como recurso comunicativo. Matrizes, São Paulo, v. 3, n. 1, dez./ago. 2009.

LOTMAN, I. Acerca de la semiosfera. In: . La semiosfera. Madrid: Cátedra, 1998. v. 1 , p. 23-42.

MACHADO, A. Pré-cinemas e pós-cinemas. Campinas: Papirus, 2002.

MARTÍN-BARBERO, J. Matrices culturales de la telenovela. Estudios sobre las Culturas Contemporâneas, Colima, v. 2, n. 5, p. 137-164, 1988. 
MEDINA, C. Notícia, um produto à venda. São Paulo: Summus, 1988.

MELO, J. M. As telenovelas da Globo. São Paulo: Summus, 1988.

MOSCOVICI, S. Representações sociais. Petrópolis: Vozes, 2003.

SODRÉ, M. A narração do fato: notas para uma teoria do acontecimento. Petrópolis: Vozes, 2009.

SPONHOLZ, L. Jornalismo, conhecimento e objetividade: ensaios de teoria do jornalismo. Florianópolis: Insular, 2009.

TODOROV, T. As estruturas narrativas. São Paulo: Perspectiva, 2003.

WOODWARD, K. Identidade e diferença: uma introdução teórico e conceitual. In: SILVA, T. Identidade e diferença: a perspectiva dos Estudos Culturais. Petrópolis: Vozes, 2000. p. 7-72.

submetido em: 13 set. 2017 | aprovado em: 08 nov. 2017 